\title{
Implementasi Benchmarking Terhadap Manajemen Pendidikan Al- Qur'an Di Wilayah Al-Hasyimiyah Pondok Pesantren Nurul Jadid Dalam Upaya Meningkatkan Mutu Pendidikan Al-Qur'an
}

\author{
Dosen Pembimbing: Dr. Akmal Mundiri, M.Pd \\ Oleh : Intania (1630500112) \\ Intankho5@gmail.com \\ Universitas Nurul Jadid \\ Probolinggo
}

\begin{abstract}
Abstrak
Benchmarking adalah metode perbandingan yang dilakukan untuk meningkatkan mutu. Benchmarking yang diterapkan dalam dunia bisnis pada saat ini telah diadopsi oleh pendidikan sebagai cara meningkatkan mutu pendidikan. Baik pendidikan formal atau informal, pendidikan umum atau pendidikan Agama Islam. Benchmarking yang diimplementasikan untuk mengetahui manajemen Pendidikan Al-Qur'an di Pondok Pesantren Nurul Jadid Wilayah Al-Hasyimiyah guna untuk membantu memberikan referensi meningkatkan mutu Pendidikan AlQur'an dilembaga lain. Pondok Pesantren adalah tempat strategis untuk pembelajaran Al-Qur'an. Selama 24 jam penuh berkumpul dan berinteraksi dengan teman membuka peluang besar untuk saling memberitahu saling berdiskusi sehingga tidak terasa bahwa waktu habis untuk belajar. Belajar bukanlah menjadi tekanan lagi melainkan menjadi sebuah kebiasaan yang menjadi kegiatan diri sendiri yang wajib dilakukan. Perbedaan tempat yang mengakibatkan suatu hal tidak dimiliki oleh lembaga formal bukanlah menjadi kelemahan tidak mampu mengadopsi manajemen Pendidikan Al-Qur'an yang diterapkan di Pondok Pesantren. Manajemen yang diterapkan dapatlah dimodifikasi menyesuaikan dengan lingkungan tempat pembelajaran tanpa mengubah dari inti bagaimana pembelajarannya. Empat dasar manajemen yang diterapkan yaitu proses perencanaan Pendidikan Al-Qur'an, proses pelaksanaan Pendidikan AlQur'an, proses pengontrolan Pendidikan Al-Qur'an dan proses evaluasi
\end{abstract}


Pendidikan Al-Qur'an. Berbagai metode yang digunakan seperti metode halaqah, metode tanya jawab, metode rileks, metode MQS ( Metode Qur'ani Sidogiri ), dan Metode PPTQ.

\section{Pendahuluan}

Benchmarking merupakan sebuah metode yang kerapkali diterapkan dalam dunia bisnis. Metode ini digunakan untuk meningkatkan mutu dalam sebuah perusahaan. Pengusaha melakukan metode ini dengan cara membandingkan perusahaannya dengan perusahaan yang lebih maju atau pengusaha dengan sengaja melakukan sebuah observasi kesebuah perusahaan dengan tujuan melihat, meneliti adakah yang sesuai dengan perusahaannya sehingga dapat diterapkan pula dalam perusahaannya. Metode ini digunakan untuk mencari rahasia yang menjadi andalannya memajukan perusahaan dengan kualitas yang tinggi.

Dalam bahasa Indonesia benchmarking dapat diartikan sebagai "patok duga”. Menurut IBM mengartikan benchmarking merupakan suatu proses berkesinambungan untuk menganalisis tata cara terbaik dengan tujuan menciptakan serta mencapai sasaran dan tujuan yang berkualitas. Sedangkan dalam beberapa pendapat lain, disebutkan bahwa benchmarking merupakan pencarian metode-metode, proses dan praktik-praktik terbaik yang dapat menjadi acuan pelaksanaan terbaik dari sebuah lembaga. ${ }^{1}$

Melihat keberhasilan besar yang telah diraih oleh metode ini dalam meningkatkan mutu akhirnya mulai diterapkan dalam dunia pendidikan. Lembaga-lembaga pendidikan mulai melakukan observasi kelebaga-lembaga pendidikan lain yang memiliki mutu diatasnya guna melakukan perbandingan dan melakukan pencarian sebuah rahasia yang menjadi andalan sekolah tersebut. Bukan hanya dalam pendidikan formal namun bencmarking ini mulai diterapkan dalam pendidikan Al-Qur' an yang dilakukan oleh pesantren-pensantren.

Pensantren adalah lembaga pendidikan yang khusus mendalami pendidikan Agama Islam. Pesantren memiliki ciri khas dimana seorang peserta didik yang kerap kali dikenal dengan santri hidup menetap dalam kurun waktu

\footnotetext{
${ }^{1}$ Taufiqur Rachman, 2013, Manajemen Kualitas. Pdf
} 
tertentu. Hidup bersama dengan santri lain sekamar atau satu atap dengan santri lain bahkan dengan seorang guru yang sering dipanggil ustadzah bagi guru putri dan ustat bagi guru putra.

Kelebihan pesantren dari lembaga lain ialah memiliki peluang lebih besar dalam hal berdiskusi. Hal tersebut dapat melatih pikiran pelajar lebih kritis lagi. Dimana seorang pelajar lebih berkembang secara akademik maupun sosial dalam lingkungan yang bernuansa pendidikan. Belajar disekolah dengan seorang guru, belajar dikamar dengan berkelompok juga didampingi oleh seorang guru hal tersebut menjadi nilai lebih bagi sebuah pesantren.

Beberapa kemampuan dimana pesantren mengharuskan setiap santri menguasainya. Melatih dan menggembleng santri memiliki kemampuan sesuai pencapaian target pesantren untuk menciptakan output yang berkualitas. Terlebih pendidikan Al-Qur'an yang harus benar-benar dikuasai oleh seorang santri.

Menjadi sebuah keharusan bagi seorang santri untuk dapat membaca AlQur'an dengan baik dan benar sesuai dengan aturan tajwid dan sesuai dengan dialek Arab. Tajwid adalah sebuah ilmu yang mempelajari tentang kaidah serta bagaimana cara membaca Al-Qur'an dengan sebaik-baiknya. ${ }^{2}$ Dialek Arab disini ialah mampu mengucapkan huruf-huruf Arab, kalimat-kalimat Arab layaknya seorang yang berbangsa Arab yang pengucapannya tanpa terpengaruh oleh bahasa Indonesia maupun bahasa Daerah.

Ruang lingkup yang dijelaskan dalam ilmu tersebut ialah makhrijul huruf ( tempat keluar huruf ), sifatul huruf ( cara pengucapan huruf ), ahkamul huruf ( hubungan antar huruf, ahkamul madd wal qasr ( panjang dan pendek ucapan, ahkamul waqaf wal ibtida' ( memulai dan menghentikan ucapan) dan pembahasan-pembahasan lainnya. ${ }^{3}$

\section{Pendidikan Al-Qur'an di Wilayah Al-Hasyimiyah Pondok Pesantren Nurul} Jadid

Pondok Pesantren Nurul Jadid wilayah Al-Hasyimiyah dalam kepengurusan lingkup kecil memiliki kepala wilayah yang ditunjuk oleh Pengasuh

\footnotetext{
${ }^{2}$ Abdul Hafidz Muhammad, 2015, Panca Keilmuan, Probolinggo: Ma'had Ali Nurul Jadid. Hal. 473.

3 ibid
} 
Wilayah Al-Hasyimiyah berdasarkan hasil pemilihan secara demokrasi oleh santri. Terdapat sekertaris wilayah, bendahara wilayah, TU wilayah, dan 5 Kepala Bagian. Untuk bagian pendidikan Al-Qur'an dibawah Kepala Bagian 1 yaitu Kepala Bagian Pendidikan dan Pembelajaran.

Pondok Pesantren Nurul Jadid Wilayah Al-hasyimiyah terdiri dari dari 15 daerah yang masing-masing daerah menempati satu gedung dan memiliki kepala daerah atau pemimpin daerah. Dalam satu daerah memiliki wali asuh dengan jumlah bervariasi. Setiap wali asuh mengayomi 10 sampai 12 santri atau anak asuh. Wali asuh ini yang bertugas mengawasi kemampuan santri, keuangan santri, kebersihan santri, dan kesehatan santri.

Di Wilayah Al-Hasyimiyah Pondok Pesantren Nurul Jadid sebelum memulai kegiatan belajar mengajar pendidikan Al-Qur'an terdapat penyeleksian kemampuan santri. Berdasarkan penyeleksian tersebut santri akan dikelompokkan bedasarkan tingkat kemampuan yang dimilikinya tanpa melirik umur dan kelas di lembaga formal. Santri diberikan pembelajaran yang sesuai dengan target pencapaian pada masing-masing kelompok.

Pendidikan Al-Qur'an tidak hanya mempelajari bagaimana membaca AlQur'an sesuai dengan kaidah yang baik namun juga bagaimana cara menulis ayat Al-Qur'an dengan benar. Melatih penulisan dimasing-masing hurufnya dan bagaimana penyambungannya dari antar huruf. Disini seorang santri harus mampu menulis ayat Al-Qur'an dengan benar tanpa melihat mushaf Al-Qur'an sekalipun.

\section{Proses Perencanaan}

Pada proses ini koordinator Pendidikan Qur'an dan bawahannya mulai merumuskan target kemampuan santri yang akan dicapai. Setelah itu akan mulai direncanakan bagaimana cara untuk melakasanakannya sehingga target yang sudah ditetapkan akan tercapai. Misalkan menentukan kemampuan apa saja yang harus dimiliki untuk menjadi Muallimat, mulai merumuskan metode-metode pembelajaran, merumuskan bagaimana bentuk evaluasi pemebelajarannya. Hasil dari keputusan tersebut sebelum diterapkan meminta persetujuan Kepala Bagian 1 yaitu Kepala Bagian Pendidikan dan Pembelajaran dan persetujuan Kepala 
wilayah. Pada tahap akhir ialah meminta restu dan doa kepada Pengasuh Wilayah Al-Hasyimiyah Pondok Pesantren Nurul Jadid.

\section{Proses Pelaksanaan}

Sebelum pembelajaran dilakukan koordinator Pendidikan al-Qur'an melakukan pengumuman terhadap muallimat, wali asuh, dan kepala daerah tentang target pencapaian, metode pembelajaran, dan semua hal yang akan membantu prose terlaksananya Pendidikan Al-Qur'an yang efektif dan efesien.

\section{Penyeleksian}

Penyeleksian ini dilakukan untuk mengelompokkan santri sesuai dengan kemampuan yang dimilikinya. Penyeleksian ini berupa tes tulis dan tes lisan. Adapun hasil dari keduanya yang menetukan dimana kelompok pembelajaran santri.

1) Penyeleksian pertama dilakukan awal masuk santri.

Santri baru akan diseleksi membaca Al-Qur'an, praktek ibadah, da tes tulis. Adapun hasilnya akan menjadi pengelompokan pembelajaran dan pembagian kamar santri. Khusus santri baru yang terkelompok dalam kelompok $\mathrm{C}$ maka akan diasramakan khusus yaitu di Daerah Al-Masruriah. Santri dengan kelompok C tidak diperbolehkan untuk mengikuti lembaga pondok yang lain misalkan lembaga pondok LPQ ( Lembaga Pendidikan Qur'an ) yang mengkhususkan untuk tahfidz dan tahsin. Kemudian setelah pembelajaran selama setahun santri akan dites ulang yang hasilnya apabila lolos santri akan dipindahkan ke daerah yang lain sesuai lembaga formal atau sesuai lembaga pondok yang diikuti.

2) Penyeleksian kedua dan seterusnya

Adapun penyeleksian kedua dan seterusnya dilakukan setiap sebelum liburan pondok. Penyeleksian tersebut sebagai bentuk evaluasi 
pembelajaran dan pembagian kelompok pembelajaran Al-Qur'an setelah liburan. Liburan yang terdapat di Pondok Pesantren Nurul Jadid ada dua yaitu liburan Maulid Nabi dan liburan Ramadhan.

Pembagian kelompok ini tidak terpengaruh oleh sedikitpun kelas formal dan umur. Murni terbagi oleh kemampuan yang dimiliki masing-masing santri. Pembagian kelompok pembelajaran Al-Qur'an ada tiga yaitu: kelompok C, B, dan A. Santri yang telah lulus dari kelompok A maka akan diangkat mejadi seorang muallimat ( seorang pengajar Al-Qur'an ).

Pada tahun terakhir kelas formal santri, kebiasaan yangg terjadi ialah “ boyong " tradisi bagai santri untuk saatnya berhenti belajar dipesantren. Maka nilai A pada pembelajaran Al-Qur'an menjadi syarat utama apabila santri ingin berhenti.

\section{Target Pencapain Pembelajaran Dalam Masing-Masing Kelompok}

\begin{tabular}{|l|l|}
\hline Kelompok & Target Pencapaian \\
\hline C & $\begin{array}{l}\text { Menguasai teori dan mampu mempratekkan } \\
\text { Makhrijul huruf dan sifatul huruf. } \\
\text { Mampu membaca dengan lancar } \\
\text { Menguasai teori dan mampu mempratekkan hukum } \\
\text { Nun mati dan tanwin } \\
\text { Menguasai teori dan mampu mempratekkan hukum } \\
\text { Mim Mati } \\
\text { Menguasai teori dan mampu mempratekkan hukum } \\
\text { Gunnah } \\
\text { Menguasai teori dan mampu mempratekkan hukum } \\
\text { Lam dan Ro' } \\
\text { Menguasai teori dan mampu mempratekkan hukum } \\
\text { Qolqolah }\end{array}$ \\
\hline
\end{tabular}




\begin{tabular}{|l|l|}
\hline B & Menguasai teori dan mampu mempratekkan ikhfa' bi \\
& makna jadid \\
Menguasai teori dan mampu mempratekkan hukum \\
madd \\
Menguasai teori dan mampu mempratekkan Idgham \\
Mutamatsilain, Mutajanisain, dan Mutaqaribain. \\
Menguasai teori dan mampu mempratekkan Waqaf \\
Menguasai teori dan mampu mempratekkan hukum \\
Gharib \\
Mampu membaca dengan lancar sesuai kaidah \\
\hline A
\end{tabular}

\section{Metode Pembelajaran Al-Qur'an}

Metode pembelajaran yang dilakukan layaknya metode pada zaman Rasulullah SAW. ialah metode halaqah dimana seorang murid duduk melingkari menghadap guru. Metode tanya jawab dimana seoranga guru menanyakan materi untuk menguji kemampuan santri dan santri bertanya apabila ada yang kurang dipahami. Metode rileks ( Pemberian nama metode ini menyesuaikan dengan nama yang lumrah digunakan oleh santri sendiri ) ialah metode melagukan dari setiap materi agar mudah dihafal.

Metode tersebut adalah metode umum yang biasa digunakan oleh para asatid di Wilayah Al-Hasyimiyah Pondok Pesantren Nurul Jadid. Jadi para asatid bebas memilih metode yang mana harus dipakai.

Terdapat metode khusus yang dipraktekkan di Wilayah Al-Hasyimiyah Pondok Pesantren Nurul Jadid dimana metode ini khusus dipakai oleh kelompok C dan kelompok A. Kelompok C menggunakan Metode Qur'ani Sidogiri ( MQS ). Metode ini menggunakan alat peraga yang membantu santri belajar mengucapkan huruf Arab sesuai dengan makhraj. Santri mendapatkan buku latihan melafalkan huruf Arab yang berjilid-jilid. Untuk naik kesetiap jilidnya santri akan dites terlebih dahulu. Dalam pelatihannya 
santri melafalkan huruf Arab dengan dilagukan. Hal tersebut membantu proses belajar dan mengajar terlihat lebih menyenangkan. Para ustadzah yang mengajar telah diberi pelatihan khusus oleh pelatih dari Sidogiri. Untuk memperoleh izin mengajar para ustadzah terlebih dahulu harus memiliki sertifikat pelatihan Metode Qur'ani Sidogirim ( MQS ).

Kelompok A khusus menggunakan PPTQ ( Program Pelatihan Terjemah Qur'an ). Karena kelompok A sudah mampu membaca Al-Qur'an sesuai kaidah maka dipertimbangkan untuk melakukan pembelajaran menghafal terjemah perkalimat.

\section{Jadwal Kegiatan Pendidikan Al-Qur'an}

\begin{tabular}{|l|l|ll|}
\hline Hari & Kegiatan & Pukul & \\
\hline Ahad & Pengajaran Al-Qur'an & $\begin{array}{l}5.30-06.00 \text { dan 18.30- } \\
19.15\end{array}$ & \\
\hline Sabtu & Evaluasi oleh Muallimat & $\begin{array}{l}5.30-06.00 \text { dan 18.30- } \\
19.15\end{array}$ & \\
\hline Senin & Pengajaran Al-Qur'an & $5.30-06.00$ dan 18.30- \\
& & 19.15 & \\
\hline Selasa & Pengajaran Al-Qur'an & $5.30-06.00$ dan 18.30- \\
& & 19.15 & \\
\hline Rabu & Evaluasi oleh Wali Asuh & $5.30-06.00$ dan 18.30- \\
& & 19.15 & \\
\hline
\end{tabular}

\section{Proses Pengontrolan}

Ketika bel otomatis telah berbunyi maka kegiatan pembelajaran Al-Qur'an dimulai. Santri akan berkumpul dengan kelompoknya masing-masing dan mengumpulkan blanko kegiatan kepada muallimat untuk meminta tanda tangan (tanda bahwa santri mengikuti kegiatan). Muallimat akan mengabsen santri, untuk santri yang telat maka diberi sanksi berdiri 15 menit dan untuk santri yang alpha maka hukuman akan diberikan oleh wali asuh yaitu menulis 50 istighfar. 
Setiap perharinya wali asuh akan mengontrol santri melalui blanko kegitan. Blanko kegiatan yang kosong tidak terisi atau terdapat alpha, maka satu kali alpha diberi sanksi 50 istighfar begitupun 2 alpha maka akan diberi sanksi 100 istighfar. Rekapan kehadiran santri akan dilaporkan kepada wali santri.

\section{Proses Evaluasi}

Proses evaluasi ini dilakukan sebagai tolak ukur keberhasilan pengajaran selama kurun waktu tertentu dan mengevaluasi kemampuan santri serta tingkat keefisienan dan keefektifitasan dari masing-masing metode yang digunakan.

1. Evaluasi setiap 6 bulan sekali

Evaluasi pembelajaran ini santri secara serentak dilakukan sebelum liburan. Sertifikat lulus dari kelompok pembelajaran masing-masing santri menjadi persyaratan utama untuk pulang liburan. Hal tersebut manjadi salah satu motivasi terbesar bagi seorang santri untuk bersemangat. Adapun seorang santri yang semakin surut rasa semangat belajar maka menjadi tugas wali asuh dan BK wilayah untuk menggali penyebab, pemberian solusi, serta dorongan motivasi baru untuk lebih semangat lagi belajar.

\section{Evaluasi Bulanan}

Dalam setiap harinya seorang muallimat ( pengajar Al-Qur'an ) melakukan pengamatan dan penilaian terhadap santri. Ketika di akhir bulan hasil rekapitulasi pengamatan dan penilaian muallimat dilaporkan kepada koordinator pendidikan Al-Qur'an di wilayah Al-Hasyimiyah Pondok Pesantren Nurul Jadid dalam bentuk tulisan. Dilaporkan dalam bentuk lisan dalam sharing muallimat yang dipimpin oleh koordinator pendidikan AQur'an sendiri. Disinilah awal munculnya solusi-solusi bagi masalah yang dialami muallimat dan awal penciptaan metode baru.

\section{Evaluasi Mingguan}

Evaluasi pembelajaran Al-Qur'an secara mingguan dilakukan oleh wali asuh masing-masing santri. Hasil dari penilain kemampuan dan pengamatan 
terhadap semangat belajar dilaporkan secara lisan ketika rapat evaluasi daerah yang dilakukan seminggu sekali tepat pada malam kamis dan dipimpin langsung oleh Penanggung jawab daerah. Pada rapat tersebut dilakukan untuk memecahkan masalah yang terjadi dalam lingkup daerah.

Adapun hasil dari rapat tersebut dilaporkan dalam bentuk tulisan ke BK Wilayah. Di Bk wilayah ditemukanlah rekapitulasi bagi santri yang rasa minatnya semakin turun dalam setiap pembelajaran. Sebagai tindak lanjutnya maka BK akan mencoba mencari tahu penyebab dan memecahkan permasalahan santri tersebut.

Hasil rekapitulasi yang dimiliki Koordinator Pendidikan Qur'an. Bk Wilayah, Kepala Daera, Penanggung Jawab Daerah akan dilaporkan dalam bentuk tulisan dan lisan ketika diadakan rapat eavaluasi bulanan oleh kepengurusan inti wilayah Al-Hasyimiyah Pondok Pesantren Nurul Jadid.

Evaluasi Al-Qur'an santri juga dilakukan di lembaga formal dan lembaga pendidikan Diniyah. Dimana hasil dari evaluasi tersebut menjadi persyaratan mengikuti ujian sekolah dan ujian Diniyah.

\section{Daftar Pustaka}

Muhammad. Abdul Hafidz. 2015. Panca Keilmuan. Probolinggo: Ma'had Ali Nurul Jadid. Hal. 473.

Taufiqur Rachman. 2013. Manajemen Kualitas. Pdf

Mundiri, A. (2017). Organizational Culture Base On Total Quality Management In Islamic Educational Institution. ADRI International Journal Of Islamic Studies and Social Sciences, 1(1), 1-11.

Mundiri, A. (2015). KOMITMEN ORGANISASIONAL SUMBER DAYA MANUSIA DALAM MENINGKATKAN MUTU PENDIDIKAN PESANTREN. Pedagogik, 3(1), 88-105. 